\title{
Exchange Rates and the News: Have We Missed the Business Cycle Relationship?
}

\author{
K. H. McIntyre ${ }^{1}$ \\ ${ }^{1}$ Department of Economics \& Business, McDaniel College, Westminster, USA \\ Correspondence: K. H. McIntyre, Deptartment of Economics \& Business, McDaniel College, 2 College Hill, \\ Westminster, MD 21157, USA. Tel: 1-410-857-2451. E-mail: mcintyre@ mcdaniel.edu
}

Received: June 27, 2015

Accepted: July 7, 2015

Online Published: August 25, 2015

doi:10.5539/ijef.v7n9p150

URL: http://dx.doi.org/10.5539/ijef.v7n9p150

\begin{abstract}
This paper investigates the relationship between fluctuations in spot exchange rates and macroeconomic news. It develops an exchange rate model that decomposes the exchange rate into both permanent and temporary components, and show that the news is linked to the temporary component of the exchange rate. Empirical findings suggest that unexpected changes in salient macroeconomic variables-the news-contribute significantly to fluctuations in the temporary component of the nominal exchange rate. This result is robust across major currencies.
\end{abstract}

Keywords: exchange rates, news, filtering

\section{Introduction}

The notorious intractability and unpredictability of exchange rates is the most vexing issue in international finance. Perhaps the one consistency in empirical exchange rate research is that even the most sophisticated models are unable to consistently track historical movements in exchange rates and to accurately forecast them over short-and medium-term time horizons, and it is not without irony that the benchmark empirical exchange rate model is the random walk (Frankel \& Rose, 1995).

While a disturbingly large portion of the volatility observed in exchange rates is unpredictable, it is not inexplicable, at least in a theoretical sense. A popular and intuitive explanation is that the seemingly white noise innovations to exchange rates are associated with news, that is, unanticipated events that discretely impact the exchange rate (Dornsbusch, 1980; Frenkel, 1981). Examples of news that in theory can be easily quantified are statistical releases containing unexpected information or surprise monetary policy; the economic definition of news, however, could be extended to include events such as shifts in market expectations, election results, speeches by central bankers and politicians, and even fits of irrationality among currency traders.

Research incorporating news variables into empirical exchange rate models has met with some success. The initial studies in this area were typically extensions of the workhorse monetary model, where fluctuations in the exchange rate were attributed to statistical innovations in interest rate differentials and other salient macroeconomic fundamentals (Dornsbusch, 1978; Frenkel, 1981), while later research focused on interest rate innovations as the primary news variable (Copeland, 1989; Grilli \& Roubini, 1995; Stillwagon, 2014). Other work in this area reincorporates innovations to other fundamental conditions (Clarida \& Galli, 1994; Edison, 1996, Pearce \& Solakoglu, 2007), and suggests other sources of exchange rate variation such as fiscal shocks (Meltzer, 1993).

These and other news studies, however, are limited by the fact that high-frequency events like news are being used to analyze raw exchange rates, which are being influenced by macroeconomic conditions at all (i.e. high, business cycle, trend) frequencies. It is therefore possible that the effect of an unexpected statistical release on the exchange rate may be overshadowed by, say, a low-frequency event like a mean reversion towards purchasing power parity. This paper addresses this issue by adapting a standard exchange rate model to decompose the spot rate into temporary and permanent components. Under mild assumptions, this model suggests that news variables affect the exchange rate through its temporary component. Empirical findings for a five major currencies (Euro, British Pound, Australian and Canadian dollar, and Japanese Yen) support this notion; by eliminating the slow-moving (PPP) component of the spot rate, I find a strong, statistically significant 
relationship exists between exchange rate and the news, while an analogous study using raw data finds only marginal evidence of such a relationship. This finding is fairly robust across countries, and to the methods used to isolate the temporary component of the spot rate.

The remainder of the paper is organized as follows: Section 2 develops an ad-hoc news model of exchange rate determination. Section 3 describes data and econometric implementation strategies. Section 4 discusses results and Section 5 concludes.

\section{A News Model}

Consider the following general model of exchange rate determination:

$$
s_{t}=\gamma z_{t}+\psi E_{t} \Delta s_{t+1}+v_{t}
$$

where $s$ is the natural logarithm of the spot exchange rate, $z$ is a vector of $m$ fundamental factors that affect the supply and demand for foreign exchange, and $\gamma$ is a coefficient vector of length $m$. $E$ is the expectations operator, and $v$ is a mean zero, serially uncorrelated error term.

Following Baxter and King (1995), any economic time series, including exchange rates, can be decomposed into orthogonal temporary $(T)$ and permanent components $(P)$ :

$$
s_{t}=s_{t}^{T}+s_{t}^{P}
$$

As an aside, an attractive theoretical-albeit anecdotal-interpretation arises from this decomposition. In particular, the permanent, or long run component of the exchange rate lends itself to long run theories of exchange rate determination and modelling, namely purchasing power parity or the random walk. Similarly, structural approaches like the standard monetary model and portfolio balance models/interest rate parity may be thought of as best describing the temporary or cyclical component of the exchange rate.

Since these frequency bands are by definition orthogonal,

$$
E_{t-1} s_{t}=E_{t-1}\left(s_{t}^{T}+s_{t}^{P}\right)=E_{t-1} s_{t}^{T}+E_{t-1} s_{t}^{P}
$$

It follows that:

$$
E_{t} \Delta s_{t+1}=E_{t} \Delta s_{t+1}^{T}+E_{t} s_{t+1}^{P}
$$

If the trend component of the exchange rate follows a random walk with drift:

$$
s_{t+1}^{P}=\mu+s_{t}^{P}+\varepsilon_{t+1}
$$

where $\mu$ is a positive scalar and $\varepsilon$ a mean-zero error term, it follows that the expected innovation in the spot exchange rate is driven by the expected innovation in its temporary component:

$$
E_{t} \Delta s_{t+1}=\mu+E_{t} \Delta s_{t+1}^{T}
$$

Plugging (2)-(4) into (1) and simplifying algebra gives:

$$
s_{t}^{T}-\frac{\psi}{1+\psi} E_{t} s_{t+1}^{T}=\frac{\psi}{1+\psi} \mu+\frac{1}{1+\psi}\left[\gamma z_{t}-s_{t}^{P}\right]+v_{t}
$$

The forward solution for $s^{T}$ is:

$$
s_{t}^{T}=\mu \sum_{j=0}^{\infty}\left(\frac{\psi}{1+\psi}\right)^{j}+\frac{1}{1+\psi} \sum_{j=0}^{\infty}\left(\frac{\psi}{1+\psi}\right)^{j} E_{t}\left[\gamma z_{t+j}-s_{t+j}^{P}\right]+v_{t}
$$

Given that the process for $s^{P}$ does not depend on $z$ (at least not in the short run), one can distribute the expectations operator without worrying about covariances. As such, the previous expression can be rewritten as:

$$
s_{t}^{T}=\mu(1+\psi)+\frac{\gamma}{1+\psi} \sum_{j=0}^{\infty}\left(\frac{\psi}{1+\psi}\right)^{j} E_{t} z_{t+j}-\left(\frac{1}{1+\psi}\right) \sum_{j=0}^{\infty}\left(\frac{\psi}{1+\psi}\right)^{j}\left(\mu j+s_{t}^{P}\right)+v_{t}
$$

where $E_{t} s_{t+j}^{P}$ is expressed as $\mu j+s_{j}^{P}$. Noting that $\sum_{j=0}^{\infty} x^{j} j \approx x$ if $|x|<1$, this can be further simplified to:

$$
s_{t}^{T}=k+s_{t}^{P}+\frac{\gamma}{1+\psi} \sum_{j=0}^{\infty}\left(\frac{\psi}{1+\psi}\right)^{j} E_{t} z_{t+j}+v_{t}
$$

where $k=\frac{\mu\left[\psi+(1+\psi)^{3}\right]}{(1+\psi)^{2}}$. Conditioning on date $t-1$ information yields: 


$$
E_{t-1} s_{t}^{T}=k+E_{t-1} s_{t}^{P}+\frac{\gamma}{1+\psi} \sum_{j=0}^{\infty}\left(\frac{\psi}{1+\psi}\right)^{j} E_{t-1} z_{t+j}
$$

Finally, taking differences and noting $E_{t-1} s_{t}^{P}=\mu+s_{t-1}^{P}$ and thus $s_{t}^{P}-E_{t-1} s_{t}^{P}=\left(\mu+s_{t-1}^{P}+\varepsilon_{t}\right)-$ $\left(\mu+s_{t-1}^{P}\right)=\varepsilon_{t}$ results in:

$$
\left(s_{t}^{T}-E_{t-1} s_{t}^{T}\right)=\frac{\gamma}{1+\psi} \sum_{j=0}^{\infty}\left(\frac{\psi}{1+\psi}\right)^{j}\left(E_{t} z_{t+j}-E_{t-1} z_{t+j}\right)+\left(v_{t}+\varepsilon_{t}\right)
$$

This is the key equation in this paper; it expresses the innovation the temporary component of the spot rate as a function of unexpected innovations in $z$ - the news - and any revision to expectations occurring between dates $t-1$ and $t$.

\section{Implementation and Estimation Strategies}

\subsection{Data and the News}

My data consists of monthly time series for the U.S. and a five country/region sample consisting of the Euro area, Australia, Canada, Japan, and the United Kingdom. The effective date range is 2001:10-2015:2. The spot rate, $s$, is the natural logarithm of FX/U.S. Dollar rate. The forward rate, $f$, is also in logs and is denoted in the same units. The exchange rate's (news) determinants consist of interest rate and inflation spreads:

$$
\begin{gathered}
i-i^{*} \\
\pi-\pi^{*}
\end{gathered}
$$

where $i$ and $\pi$ denote the nominal interest and inflation rates, respectively, and superscript "**"s denote foreign (i.e. non-U.S.) quantities. Interest rates are measured using the 10-year yield on government debt, and inflation using year-ago percentage changes in the consumer price index (CPI). ${ }^{2}$ The news is then defined as the one-month ahead forecast error associated with the above yield and inflation spreads:

$$
\begin{gathered}
\left(i_{t}-i_{t}^{*}\right)^{N E W S}=\left(i_{t}-i_{t}^{*}\right)-E_{t-1}\left(i_{t}-i_{t}^{*}\right) \\
\left(\pi_{t}-\pi_{t}^{*}\right)^{N E W S}=\left(\pi_{t}-\pi_{t}^{*}\right)-E_{t-1}\left(\pi_{t}-\pi_{t}^{*}\right)
\end{gathered}
$$

where $E_{t-1}\left(i_{t}-i_{t}^{*}\right)$ and $E_{t-1}\left(\pi_{t}-\pi_{t}^{*}\right)$ represent forecasted values. Forecasts of U.S. and foreign interest and inflation rates are obtained from surveys collected and compiled by FX4Casts (Note 1).

\subsection{Isolating the Temporary Component of the Spot Rate}

I examine three methods for isolating the temporary component of the spot rate. The first is via the application of a band-pass filter as detailed in Baxter and King (1999) and Christiano and Fitzgerald (1999). I set this filter to isolate the "business cycle component" of the spot rate, that is, movements in the data between 18-96 months, the average duration of business cycles isolated by NBER researchers using the methods of Burns and Mitchell (1935). It is important to note that in addition to removing the permanent component of an economic time series, the band pass filter also removes a high-frequency or irregular component, which is typically associated with white noise. This is an attractive feature with regard to exchange rate data since it eliminates the risk that transient noise might disguise the underlying business cycle component of the data, which is ideally impacted by the news. It is also important to note, that the high frequency component of the exchange rate provides little variance to the overall spot rate. For example, in terms of a source of variance, the irregular component of the spot rate is most important for the United Kingdom, were it contributes $2 \%$ to the total variance of both the spot and forward rates, respectively.

In addition to the band-pass filter, I also detrend the spot rate using the common and well-known Hodrick-Prescott (1997) filter with the smoothing parameter $\lambda$ set to 14,400 , the benchmark value when dealing with monthly data. With regard to low frequencies, the Hodrick-Prescott and band-pass filter trends are virtually identical. The primary difference between the two filters, however, is that the Hodrick-Prescott filter is a "high pass" filter, that is, an economic time series detrended using the Hodrick-Prescott filter retains both a business cycle and high frequency component. As such, comparison of empirical results from the band pass and Hodrick-Prescott filtered data will thus give some insight into the role the high frequency, or irregular component of the spot rate plays in overall exchange rate tractability.

My final method is the well-known and well-documented Beveridge-Nelson (1981) univariate decomposition, which suggests that the temporary component of the spot rate is given by: 


$$
s_{t}^{T}=-E_{t}\left[\sum_{j=1}^{\infty} \Delta s_{t+j} \mid \Delta s_{t}, \Delta s_{t-1}, \ldots\right]
$$

and its permanent component as:

$$
s_{t}^{P}=s_{t}+E_{t}\left[\sum_{j=1}^{\infty} \Delta s_{t+j} \mid \Delta s_{t}, \Delta s_{t-1}, \ldots\right]
$$

where $s^{P}$ is a martingale. Combining these two equations gives one (2). I implement this decomposition using the algorithm outlined in Newbold (1990), by first fitting an $\operatorname{ARIMA}(p, 1, q)$ to the spot and forward rates, where $p$ and $q$ are set using the Box-Jenkins (1976) methodology, defining this as $s^{P}$, and subsequently obtaining the temporary component residually.

The temporary components returned by these techniques are different in many respects. As illustrated in Figure 1, the band-pass filter returns a temporary component that appears much smoother than the Hodrick-Prescott method, a result of the fact that it removes a high-frequency component. That said, the standard deviation of each series, reported in Table 1, is approximately the same. In contrast, the Beveridge-Nelson decomposition typically exhibits the least volatile temporary component; with the lone exception of the Euro, the standard deviation of the Beveridge-Nelson component is approximately one-quarter to one-half that of the band-pass and Hodrick-Prescott filtered data. Finally and given their similar methodologies, the band-pass and HP temporary components are strongly correlated.
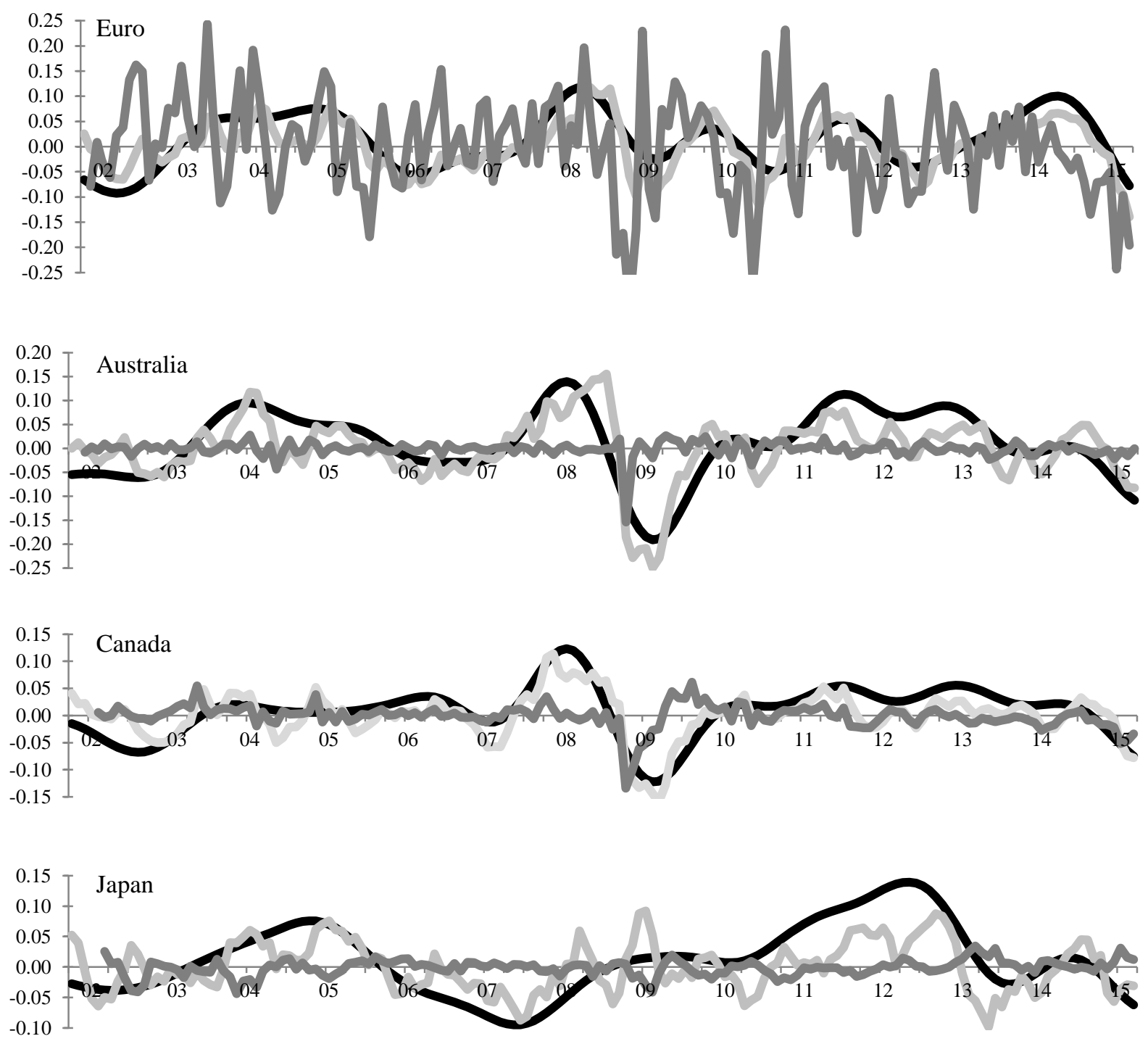


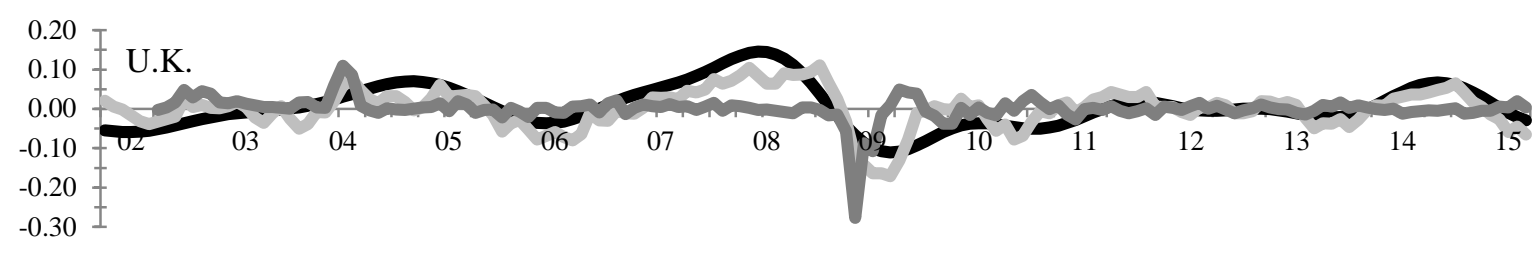

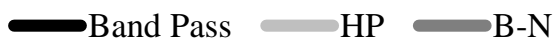

Figure 1. Temporary component of spot rates

As noted in Table 1, the correlation between these two temporary components is typically in excess of +0.75 . Again the exception, the Beveridge-Nelson temporary component is weakly correlated with the other two measures of the temporary component of the spot rate, and in the case of the Japanese Yen, is negatively correlated with the band-pass and Hodrick-Prescott series.

Table 1. Statistical properties of filtered spot rates

\begin{tabular}{lcccc}
\hline & Standard deviation & \multicolumn{2}{c}{ Correlation matrix } & \\
\hline Euro & & & & \\
Band Pass & 0.052 & 1.000 & & \\
Hodrick Prescott & 0.048 & 0.793 & 1.000 & 1.000 \\
B-N & 0.097 & 0.057 & 0.286 & \\
\hline Australian Dollar & & & & \\
Band Pass & 0.070 & 1.000 & & 1.000 \\
Hodrick Prescott & 0.066 & 0.780 & 1.000 & \\
B-N & 0.016 & 0.040 & 0.184 & \\
\hline Canadian Dollar & & & & \\
Band Pass & 0.047 & 1.000 & & \\
Hodrick Prescott & 0.043 & 0.789 & 1.000 & \\
B-N & 0.022 & 0.209 & 0.452 & \\
\hline Japanese Yen & & & & \\
Band Pass & 0.057 & 1.000 & & \\
Hodrick Prescott & 0.041 & 0.653 & 1.000 & \\
B-N & 0.013 & -0.115 & -0.464 & \\
\hline British Pound & & & & \\
Band Pass & 0.054 & 1.000 & & \\
Hodrick Prescott & 0.049 & 0.765 & 1.000 & \\
B-N & 0.031 & 0.131 & 0.284 & \\
\hline
\end{tabular}

\subsection{Estimating Equation}

Transforming (5) into an estimating equation, namely quantifying last period's expectation of the current spot rate's temporary component, $E_{t-1} s_{t}^{T}$, is a somewhat involved process. Regarding this term, if there is an established forward market for the currency in question, one can express last period's expectation of the temporary component of the current spot rate by using the temporary component of the forward rate, $f^{T}$, and a vector of other relevant variables influencing agents' expectations formation, $a$ :

$$
E_{t-1} s_{t}^{T}=a_{t}+f_{t-1}^{T, t}
$$

Expressions such as this are frequently observed in conjunction with tests of forward market efficiency, where one would estimate an equation of the form ( $\eta$ is the error term):

$$
E_{t-1} s_{t}^{T}=a+c f_{t-1}^{T, t}+\eta_{t}
$$

and test the joint hypothesis $a=0$ and $c=1$.

Following Copeland (1989), the temporary component of the forward rate will be a reasonable proxy for the 
expected temporary component of the spot rate if two conditions are met. First, $a_{t}=a_{t+j}=a \forall j$. That is, the risk premium associated with the forward rate is constant. Second and most important, $\eta$ must not be serially correlated, implying that there are no arbitrage opportunities available in the forward market. (If such opportunities existed, the implication is that the forward rate is not accurately reflecting market expectations and/or agents are forming irrational expectations regarding future spot rates.) The first condition can be imposed by assumption, and the second can be achieved via estimating (7) using an appropriate GMM technique.

Additionally, one would ideally prefer $c$ to be unity. Although not a necessary condition, values of $c$ that differ significantly from one are problematic to interpret, especially if $\eta$ did not exhibit serial correlation. Following efficient market theory, I impose this condition. Substituting this setup into (5) and making a notational simplification yields the following regression equation:

$$
s_{t}^{T}=a+f_{t-1}^{T, t}+\Phi \cdot N E W S_{t}+u_{t}
$$

where $\Phi=\gamma /(1+\psi)$ and $u_{t}=v_{t}+\varepsilon_{t}+\eta_{t}$. (10) is then estimated via OLS, where the coefficient on the forward rate is restricted to unity.

\section{Results}

The results obtained from estimating (11) are reproduced in Table 2. For each country four sets of results are presented, based alternate exchange rate decompositions and for comparison purposes, results obtained from estimating (11) using raw (non-filtered) exchange rate data. Of primary interest are the results of two hypothesis tests: first, the whether or not individual news variables significantly impact the temporary component of the spot rate, and second, whether or not news variables jointly impact the temporary component of the spot rate. The latter tests the null hypothesis $\mathrm{H}_{0}$ : $\Phi=0$.

Some broad generalities can be drawn from these results. First, it is the case that the coefficient on interest rate news is significant in all but one case (the Beveridge-Nelson decomposition for the British Pound) and is typically significant at the $1 \%$ level or better. All significant interest rate news variables also have the correct (negative) sign regardless of how the temporary component of the exchange rate is measured, that is, unexpectedly higher interest rates in the U.S. result in an appreciation the business cycle component of the U.S. dollar. The fact that the interest differential and the exchange rate are so strongly linked is not surprising and is consistent with prior research; Eichenbaum and Evans (1995), for example, find a similarly strong link between interest rate innovations and exchange rate fluctuations in their structural VAR study, as do Baxter (1994) and Copeland (1989) in their news studies.

Table 2. News model results

\begin{tabular}{|c|c|c|c|c|c|}
\hline \multicolumn{6}{|l|}{ Euro } \\
\hline Filter & Constant & Interest Rate NEWS & Inflation NEWS & $\chi^{2}, \boldsymbol{\Phi}=0$ & p-value \\
\hline Band Pass & $\begin{array}{c}-0.0021^{* *} \\
(0.0006)\end{array}$ & $\begin{array}{c}-0.0024 * * \\
(0.0005)\end{array}$ & $\begin{array}{c}0.0015^{* *} \\
(0.0006)\end{array}$ & 25.58 & 0.0000 \\
\hline Hodrick-Prescott & $\begin{array}{c}-0.0047 * \\
(0.0021)\end{array}$ & $\begin{array}{c}-0.0058^{* *} \\
(0.0009)\end{array}$ & $\begin{array}{c}0.0007 \\
(0.0216)\end{array}$ & 40.39 & 0.0000 \\
\hline Beveridge-Nelson & $\begin{array}{l}-0.0084 \\
(0.0053)\end{array}$ & $\begin{array}{c}-0.0121 * * \\
(0.0046)\end{array}$ & $\begin{array}{c}0.0063 \\
(0.0051)\end{array}$ & 12.63 & 0.0018 \\
\hline Raw & $\begin{array}{c}-0.0066^{* * *} \\
(0.0016) \\
\end{array}$ & $\begin{array}{l}-0.0056 \\
(0.0130) \\
\end{array}$ & $\begin{array}{c}0.0019 \\
(0.0016) \\
\end{array}$ & 0.12 & 0.2551 \\
\hline \multicolumn{6}{|l|}{ Australian Dollar } \\
\hline Filter & Constant & Interest Rate NEWS & Inflation NEWS & $\chi^{2}, \boldsymbol{\Phi}=0$ & p-value \\
\hline Band Pass & $\begin{array}{c}-1.3796^{* *} \\
(0.0114)\end{array}$ & $\begin{array}{c}-0.5651 * * \\
(0.0314)\end{array}$ & $\begin{array}{c}0.0745^{* *} \\
(0.0075)\end{array}$ & 45.06 & 0.0000 \\
\hline Hodrick-Prescott & $\begin{array}{c}-0.2249 * * \\
(0.0067)\end{array}$ & $\begin{array}{c}-0.1031^{* *} \\
(0.0114)\end{array}$ & $\begin{array}{c}0.2476^{* *} \\
(0.0118)\end{array}$ & 18.51 & 0.0000 \\
\hline Beveridge-Nelson & $\begin{array}{c}-0.0009 * * \\
(0.0003)\end{array}$ & $\begin{array}{c}-0.0227 * * \\
(0.0017)\end{array}$ & $\begin{array}{c}0.0136^{* *} \\
(0.0016)\end{array}$ & 12.16 & 0.0023 \\
\hline Raw & $\begin{array}{c}-1.5074 * * \\
(0.0124)\end{array}$ & $\begin{array}{l}-0.0691 \\
(0.1217) \\
\end{array}$ & $\begin{array}{c}0.2485 \\
(0.1398) \\
\end{array}$ & 3.97 & 0.1374 \\
\hline
\end{tabular}




\begin{tabular}{|c|c|c|c|c|c|}
\hline \multicolumn{6}{|l|}{ Canadian Dollar } \\
\hline Filter & Constant & Interest Rate NEWS & Inflation NEWS & $\chi^{2}, \boldsymbol{\Phi}=0$ & p-value \\
\hline Band Pass & $\begin{array}{c}-0.0020 * * \\
(0.0004)\end{array}$ & $\begin{array}{l}-0.0026^{*} \\
(0.0012)\end{array}$ & $\begin{array}{c}0.0017 * * \\
(0.0004)\end{array}$ & 18.83 & 0.0000 \\
\hline Hodrick-Prescott & $\begin{array}{c}-0.0070^{* * *} \\
(0.0016)\end{array}$ & $\begin{array}{c}-0.0071 * * \\
(0.0027)\end{array}$ & $\begin{array}{l}0.0048^{*} \\
(0.0019)\end{array}$ & 13.82 & 0.0001 \\
\hline Beveridge-Nelson & $\begin{array}{c}-0.0034 * * \\
(0.0013)\end{array}$ & $\begin{array}{l}-0.0066^{*} \\
(0.0026)\end{array}$ & $\begin{array}{l}0.0025 * \\
(0.0011)\end{array}$ & 8.65 & 0.0132 \\
\hline Raw & $\begin{array}{l}-0.0006 \\
(0.0015) \\
\end{array}$ & $\begin{array}{c}-0.0081 * * \\
(0.0031) \\
\end{array}$ & $\begin{array}{l}-0.0006 \\
(0.0016) \\
\end{array}$ & 4.88 & 0.0872 \\
\hline \multicolumn{6}{|l|}{ Japanese Yen } \\
\hline Filter & Constant & Interest Rate NEWS & Inflation NEWS & $\chi^{2}, \boldsymbol{\Phi}=0$ & $\mathrm{p}$-value \\
\hline Band Pass & $\begin{array}{c}-0.0016^{* * *} \\
(0.0005)\end{array}$ & $\begin{array}{c}-0.0067 * * \\
(0.0011)\end{array}$ & $\begin{array}{c}0.0009 * * \\
(0.0002)\end{array}$ & 54.89 & 0.0000 \\
\hline Hodrick-Prescott & $\begin{array}{c}-0.0040^{* *} \\
(0.0011)\end{array}$ & $\begin{array}{c}-0.0051^{* *} \\
(0.0015)\end{array}$ & $\begin{array}{c}0.0022 * * \\
(0.0006)\end{array}$ & 25.29 & 0.0000 \\
\hline Beveridge-Nelson & $\begin{array}{c}0.0018^{* *} \\
(0.0001)\end{array}$ & $\begin{array}{l}-0.0022 * \\
(0.0010)\end{array}$ & $\begin{array}{c}0.0009^{* *} \\
(0.0003)\end{array}$ & 16.85 & 0.0002 \\
\hline Raw & $\begin{array}{c}-0.0147 * * \\
(0.0016)\end{array}$ & $\begin{array}{l}-0.0103 \\
(0.0274)\end{array}$ & $\begin{array}{l}-0.0029 \\
(0.0089)\end{array}$ & 0.85 & 0.6538 \\
\hline \multicolumn{6}{|l|}{ British Pound } \\
\hline Filter & Constant & Interest Rate NEWS & Inflation NEWS & $\chi^{2}, \boldsymbol{\Phi}=0$ & $\mathrm{p}$-value \\
\hline Band Pass & $\begin{array}{c}-0.0013^{*} \\
(0.0006)\end{array}$ & $\begin{array}{c}-0.0057 * * \\
(0.0015)\end{array}$ & $\begin{array}{l}.0020 * * \\
(0.0003)\end{array}$ & 61.91 & 0.0000 \\
\hline Hodrick-Prescott & $\begin{array}{l}-0.0004 \\
(0.0004)\end{array}$ & $\begin{array}{c}-0.0032^{* *} \\
(0.0011)\end{array}$ & $\begin{array}{c}0.0014 * * \\
(0.0003)\end{array}$ & 32.73 & 0.0000 \\
\hline Beveridge-Nelson & $\begin{array}{c}0.0033 \\
(0.0018)\end{array}$ & $\begin{array}{c}0.0086 \\
(0.0067)\end{array}$ & $\begin{array}{c}0.0042^{* *} \\
(0.0015)\end{array}$ & 8.02 & 0.0181 \\
\hline Raw & $\begin{array}{c}0.0009 * * \\
(0.0002)\end{array}$ & $\begin{array}{l}-0.0008 * \\
(0.0004)\end{array}$ & $\begin{array}{c}0.0002 \\
(0.0001)\end{array}$ & 4.50 & 0.1054 \\
\hline
\end{tabular}

Notes. 1). All exchange rate are in $\mathrm{FX} / \$$ form.

2). Standard error in parentheses.

3). * significant at the .05 level; ** significant at the .01 level.

4). $\chi^{2}$ is for testing the joint hypothesis that all news coefficients are equal to zero ( $\left.2 \mathrm{df}\right)$; the p-value for this test is reported in the next column.

Second, inflation differential news is typically a significant determinant of the business cycle component of the exchange rate. Exceptions are found with the Hoderick-Prescott and Beveridge-Nelson results for the Euro. Although somewhat disappointing, this finding is likely the result of the high frequency component these two filtering methodologies keep, and is removed when using band-pass filters. With the other four currencies considered, however, one does observe strongly significant inflation differential news variables for all filters employed. And as is the case with yield spread news, inflation differential news is, when significant of the correct (positive) sign; a surprise increase in relative U.S. inflation weakens the temporary component of the U.S./FX exchange rate.

Third, the news is uniformly an important determinant of the temporary component of the exchange rate. The news was jointly significant at $5 \%$ or better in all fifteen news models estimated using the exchange rate's temporary component, and in all but two cases, significant at $1 \%$ or better. These results are expected given the strong patterns of statistical significance observed with individual news variables.

Lastly, the results associated with estimating the model with raw exchange rate data are uniformly poor. Significant news coefficients are rare and are only found with yield spread news; inflation differential news is never significant with raw exchange rate data. Not surprisingly, the news is never jointly significant when the model is estimated using raw data. These poor results are consistent with two generations of research in empirical international finance, and are an endorsement of the business cycle approach developed in this paper. 


\section{Conclusion}

Since the collapse of Bretton Woods, considerable research has been done in an effort to develop an accurate exchange rate model based on economic fundamentals. Such efforts, however, have not stood up well over time, and the random walk model remains the best model that economists have for tracking exchange rates. So-called news models of the exchange rate constructed by replacing fundamental variables with their statistical innovation have been more successful than standard fundamental models, although the existence of a stable, statistically significant relationship between the news and the nominal exchange rate is often debatable.

This paper suggests that it is most appropriate to examine the relationship between the news and the temporary of the exchange rate. The intuition behind this approach is that the impact of obviously high-frequency events like news on currency valuations may be overshadowed in a statistical sense by the exchange rate's low-frequency time series component. I accordingly conduct my analysis after first filtering our exchange rate data to isolate its temporary component. To address the issue of robustness, I consider alternate methods to decompose the exchange rate.

The results are on the whole quite promising. I find that interest rate and inflation news is a significant determinant of the temporary component of the spot rate and that decomposing the exchange rate results in a clear improvement in model performance over those estimated with raw exchange rate data. More importantly, these results are also robust across currencies and to alternate decompositions of the exchange rate. Further inquiry is certainly required, but these findings suggest that frequency analysis provides an avenue to better our understanding of exchange rate determination and fluctuations.

\section{Acknowledgements}

With apologies to Marianne Baxter (1994).

\section{References}

Baxter, M. (1994). Real Exchange Rates and Real Interest Rates: Have We Missed the Business Cycle Relationship? Journal of Monetary Economics, 33, 5-38. http://dx.doi.org/10.1016/0304-3932(94)90012-4

Beveridge, S., \& Nelson, C. (1981). A New Approach to Decomposition of Economic Time Series into Permanent and Transitory Components with Particular Attention to Measurement of the 'Business Cycle'. Journal of Monetary Economics, 7, 151-174. http://dx.doi.org/10.1016/0304-3932(81)90040-4

Box, G., \& Jenkins, M. (1976). Time Series Analysis: Forecasting and Control. San Francisco: Holden-Day.

Burns, A., \& Mitchell, W. (1935). The National Bureau's Measures of Cyclical Behavior. NBER Research Bulletin, 1-20.

Christiano, L., \& Fitzgerald, T. (1999). The Band Pass Filter. NBER Working Paper \#7257.

Clarida, R., \& Galli, J. (1994). Sources of Real Exchange Rate Fluctuations: How Important Are Nominal Shocks? NBER Working Paper \#4658.

Copeland, L. (1989). Exchange Rates and News: A Vector Autogression Approach. In R. MacDonald, \& M. Taylor (Eds.), Exchange Rates and Open Economy Macroeconomics (pp. 218-238). Oxford, UK: Blackwell.

Dornsbusch, R. (1980). Exchange Rate Economics: Where Do We Stand? Brookings Papers on Economic Activity, 1, 143-194. http://dx.doi.org/10.2307/2534287

Edison, H. (1996). The Reaction of Exchange Rates and Interest Rates to News Releases. Federal Reserve Board of Governors International Finance Discussion Paper \#570.

Frankel, J., \& Rose, A. (1995). Empirical Research on Nominal Exchange Rates. In G. Grossman, \& K. Rogoff (Eds.), Handbook of International Economics (Vol. III, pp. 1689-1729). Amsterdam: Elsevier.

Frenkel, J. A. (1981). Flexible Exchange Rates, Prices, and the Role of 'News.' Journal of Political Economy, 89, 665-705. http://dx.doi.org/10.1086/260998

Grilli, V., \& Roubini, N. (1995). Liquidity and Exchange Rates: Puzzling Evidence from the G-7 Countries. Manuscript, Yale University.

Hodrick, R. J., \& Prescott, E. C. (1997). Postwar U.S. Business Cycles: An Empirical Investigation. Journal of Money, Credit, and Banking, 29(1), 1-16. http://dx.doi.org/10.2307/2953682

King, R. (1999). Measuring Business Cycles: Approximate Band Pass Filters for Economic Time Series. Review of Economics and Statistics, 81(4), 575-593. http://dx.doi.org/10.1162/003465399558454 
Meltzer, A. (1993). Real Exchange Rates: Some Evidence From the Postwar Years. FRB St. Louis Review, (March/April), 103-107.

Newbold, P. (1990). Precise and Efficient Computation of the Beveridge-Nelson Decomposition of Economic Time Series. Journal of Monetary Economics, $453-457$. http://dx.doi.org/10.1016/0304-3932(90)90007-Q

Pearce, D., \& Solakoglu, N. (2007). Macroeconomic News and Exchange Rates. Journal of International Financial Markets, Institutions, and Money, 17(4), 307-325. http://dx.doi.org/10.1016/j.intfin.2005.12.004

Stillwagon, J. (2014). Exchange Rate Dynamics and Forecast Errors about Persistently Trending Fundamentals. Manuscript, Trinity College.

\section{Notes}

Note 1. A possible issue here is announcement effects, that is, the data and the news variables constructed in these studies use final (revised) data, which is often different than the numbers initially announced. Prior research has addressed this issue by obtaining actual press releases, etc. when constructing news variables; it is beyond the scope of this paper for us to do this. I do, however, suggest that news variables constructed using forecast errors do incorporate a "revision effect" of sorts; that is, this month's news is based on: (1) the unexpected component of this month's data point and (2) the revised information from last month's release.

Note 2. Australian CPI data is released at quarterly frequencies only. This index was converted to a monthly frequency using a naïve cubic spline interpolator. Year-ago inflation rates were then calculated from the interpolated series.

\section{Copyrights}

Copyright for this article is retained by the author(s), with first publication rights granted to the journal.

This is an open-access article distributed under the terms and conditions of the Creative Commons Attribution license (http://creativecommons.org/licenses/by/3.0/). 